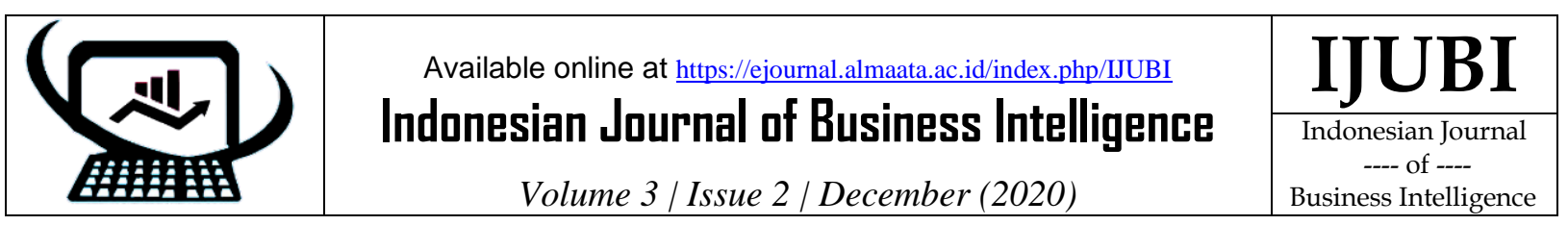

\title{
APLIKASI PEMESANAN MAKANAN UNTUK MENINGKATKAN PENJUALAN BAGI UMKM BERBASIS ANDROID
}

\author{
Pujianto ${ }^{1}$ \\ 1Program Studi Informatika, Fakultas Teknik dan Komputer, Universitas Baturaja, \\ pujianto.mail@gmail.com, \\ J1. Ratu Penghulu No.2301, Karang Sari, Baturaja, Tj. Baru, Kec. Baturaja Timur, Kab. OKU, Sumsel
}

Keywords:

UMKM, Order

Food, Android

\section{Kata Kunci:}

UMKM, Pesan Makanan, Android.

\begin{abstract}
Usaha Mikro Kecil dan Menangah (UMKM) are one of the drivers of the economy in Indonesia. UMKM are the focus of the Indonesian government, where UMKM provide $60.3 \%$ of their contribution to Indonesia's total PDP (Gross Domestic Product). UMKM are also able to accommodate a workforce of $97 \%$ of the total workforce and $99 \%$ of the total employment. To increase competitiveness for UMKM, it is necessary to digitize sales in carrying out their business processes. The formulation in this research is how to make an application that can be used to order food using Android for UMKM. This study aims to create an Android-based food ordering application for UMKM. This research method uses research and development methods, while system development uses the waterfall model. This study produces a food ordering application that can be used by users in ordering the desired food according to the menu displayed. The food ordering process is very simple and the system will validate before the food is ordered from MSME players. Before the system is used, the application is tested regarding the features in the application. With this application, it is expected to increase sales for UMKM that have joined so that they can improve the economy.
\end{abstract}

Abstrak
Usaha Mikro, Kecil dan Menengah (UMKM) adalah salah satu penggerak
roda perekonomian di Indonesia. UMKM menjadi fokus pemerintah
Indonesia, dimana UMKM memberikan 60,3\% kontribusinya terhadap total
PDP (Produk Domestik Bruto) Indonesia. UMKM juga mampu menampung
tenaga kerja sebanyak 97\% dari keseluruhan tenaga kerja dan 99\% dari
keseluruhan lapangan pekerjaan. Untuk meningkatkan daya saing bagi
UMKM diperlukan digitalisasi penjulan dalam melakukan proses bisnisnya.
Rumusan dalam penelitian ini adalah bagaimana membuat sebuah aplikasi
yang dapat digunakan untuk memesan makanan menggunakan Android
bagi UMKM. Penelitian ini bertujuan membuat aplikasi pemesanan makanan
bagi UMKM berbasis Android. Metode penelitia ini menggunakan metode
research and development, sedangkan pengembangan sistem menggunakan
waterfall model. Penelitian ini menghasilkan sebuah aplikasi pemesanan
makanan yang dapat digunakan oleh pengguna dalam memesan makanan
yang diinginkan sesuai dengan menu yang ditampilkan. Proses pemesanan
makanan sangat simpel dan sistem akan melakukan validasi sebelum
makanan dipesan ke pelaku UMKM. Sebelum sistem digunakan dilakukan
pengujian terhadap aplikasi terkait fitur-fitur yang ada pada aplikasi. Dengan
adanya aplikasi ini diharapkan dapat meningkatkan penjualan bagi UMKM
yang telah bergabung sehingga dapat meningkatkan perekonomian.




\section{Pendahuluan}

Usaha Mikro Kecil dan Menengah (UMKM) adalah salah satu penggerak roda perekonomian di Indonesia. Saat krisis ekonomi terjadi pada tahun 1998 UMKM ini sangat berdampak sehingga banyak yang harus tutup karena tidak mampu untuk beradaptasi dengan keadaan yang ada. Banyak tutupnya UMKM ini berdampak pada perekonomian nasional. Saat pandemi ini juga UMKM berdampak yang disebabpkan permintaan dari konsumen berkurang sehingga menyebapkan turunnya pendapatan dari para pelaku usaha ini. Berdasarkan data dari BPS (Badan Pusat Statistik) jumlah pelaku Usaha Mikro Kecil dan Menengah (UMKM) sejumlah 64 juta. Hal ini menunjukan bahwa 99,9 persen merupakan dari seluruh usaha yang ada di Indonesia.

Kondisi Pandemi covid-19 berdampak pada UMKM dan banyak usaha yang terhenti sekitar 30 persen yang usaha UMKM yang ada terganggu. sebagian pelaku UMKM yang ada melakukan berbagai inovasi-inovasi kreatif sekitar 50-70 persen. UMKM menjadi fokus pemerintah Indonesia dimana UMKM mampu memberikan 60,3\% kontribusinya terhadap total PDP (Produk Domestik Bruto) Indonesia. UMKM juga mampu menampung tenaga kerja sebanyak 97\% dari keseluruhan tenaga kerja dan 99\% dari keseluruhan lapangan pekerjaan.

BPS (Badan Pusat Statistik) melakukan survei dengan tema dampak pandemi Covid-19 terhadap para pelaku usaha yang dilaksanakan pada 10-26 Juli 2020, pada surve yang telah dilakukan terdapat $42 \%$ pelaku usaha hanya mampu bertahan selama 3 bulan, yaitu pada bulan Juli sampai dengan bulan Oktober 2020. Sedangkan 58\% lainnya mampu bertahan di atas 3 bulan. Perkiraan ini muncul bila tidak ada campur tangan dari permerintah terkait kondisi pandemi ini. Survei dilakukan dengan jumlah responden 34.559 yang terdiri dari 25.256 UMK (Usaha Mikro dan Kecil), 6.821 UMB (Usaha Menengah dan Besar), dan 2.482 pada bidang pertanian.

Pertumbuhan UMKM di beberapa kota-kota besar terus menunjukkan peningkatan, kususnya kota-kota yang memiliki bran kota pelajar. Kota yang memiliki brand kota pelajar akan menjadi salah satu kota tujuan para pelajar maupun mahasiswa dari berbagai daerah, hal ini menjadi potensi besar bagi UMKM guna pengembangan usahanya, khususnya di sektor makanan dan minuman. Sektor makanan dan minuman akan tetap bertahan dan bahkan bisa berkembang serta dapat menjadi andalan karena hal ini didukung oleh banyaknya permintaan dari konsumen di pasar domestik. Banyak pelaku UMKM yang membidik pelajar dan mahasiswa sebagai target konsumen untuk usahanya, sehingga tidak heran usaha di sektor makanan dan minuman kian menjamur.

Untuk meningkatkan penjualan dan agar tetap eksis pada era pendemi ini para pelaku UMKM melakukan inovasi dengan cara digitalisasi pemasaran. Banyak pelaku UMKM kususnya yang bergerak dibidang makanan melakukan promosi dan melakukan penjualan diberbagai kanal. Ada beberapa UMKM yang melakukan marketing penjualan produk melalui kanal media sosial ada juga yang melakukan penjualan produk makanan bergabung ke markekpalce adan ada juga beberapa UMKM melakukan inovasi membuat aplikasi pemesanan makan.

\section{Landasan Teori}

Perancangan aplikasi pemesanan makanan dapat dibuat dengan menerapkan teknologi firebase realtimedatabase berbasis android karena firebase memiliki banyak fitur seperti authentication, database, storage, hosting, pemberitahuan sehingga dapat mempermudah pelanggan dalam melakukan proses pemesanan makanan tanpa harus menunggu lama. Melihat dari beberapa tahapan yang telah dilaksanakan sarta hasil-hasil yang telah dicapai secara umum aplikasi ini telah bekerja cukup baik dimana pelanggan dapat melakukan pemesanan makanan sebelum berada di tempat makan sehingga dapat menghemat waktu. Penggunaan teknologi Firebase menjadikan proses pemindahan data cepat dan aman. Saran pengembangan aplikasi adalah menambahkan fitur google maps sehingga pelanggan lebih dipermudah dalam pencarian tempat makan dan juga dapat menambahkan fitur android pay untuk proses pembanyaran sehingga pelanggan tidak perlu lagi bertemu dengan pelayan untuk proses pembayaran [1]. 
Konsep Model View Controller yang umum dipergunakan untuk aplikasi Website, dapat juga diaplikasikan dalam pemrograman berbasis Android yang menerapkan penggunaan database pada web server. Bahasa pemrograman PHP dan basis data MySQL dipergunakan sebagai Controller dan Model bagi aplikasi, untuk dapat melayani organisasi data yang secara dinamis dan terpusat.

Sedangkan penerapan Android 3rd party library dapat meningkatkan kualitas dari aplikasi, juga mempermudah serta mempercepat proses pengembangannya. Penggunaan Firebase SDK dan Google API sangat menguntungkan baik untuk pengembang maupun pengguna aplikasi [2].

Bisnis restoran merupakan salah satu bidang yang menjanjikan banyak keuntungan. Namun dalam beberapa kasus, tidak semua restoran dapat menjalankan bisnisnya dengan lancar. Misalnya karena kurangnya promosi jenis makanan yang ditawarkan, maka Variasi menu yang disajikan karena proses pelayanan pelanggan kurang memuaskan. Penelitian ini ditujukan kepada Restoran 1953 Indonesia, karena permasalahan tersebut di atas dialami oleh Restoran 1953 Indonesia. Untuk itu diperlukan suatu sistem yang dapat mengatasi permasalahan dalam bisnis restoran saat ini. Bahwa Dengan begitu, aplikasi ini dapat mempermudah customer dalam melakukan pemesanan dan Restoran 1953 Indonesia dalam menyediakannya pelayanan terbaik [3].

Teknologi yang semakin berkembang pesat akan membantu dan mempermudah aktivitas manusia dalam menyelesaikan pekerjaannya. Salah satu teknologi yang berkembang pesat adalah Internet, teknologi ini merupakan bagian dari teknologi informasi. Internet dapat diakses dengan mudah dengan menggunakan mobile phone. Fasilitas internet (cloud) seharusnya bisa dimanfaatkan dengan maksimal sehingga menjadi lebih terarah dan efisien. Salah satu efektifitas internet yang dapat diterapkan adalah membantu pihak restoran khususnya dalam melakukan dan menangani layanan pemesanan makanan. Aplikasi order makanan menggunakan teknologi cloud adalah aplikasi android yang membantu user untuk melakukan pemesanan makanan tanpa harus melakukan telepon atau datang langsung ke restoran dengan bantuan internet (cloud). Untuk penggunaannya Aplikasi ini wajib terhubung dengan akses internet (cloud) untuk bisa mengakses restoran yang terdaftar pada sistem. Hasil dari implementasi aplikasi ini adalah dapat memudahkan pemesanan makanan bagi masyarakat, khususnya bagi orang-orang yang memiliki banyak kesibukan [4].

Salah satu cara mempermudah pelanggan dalam memesan makanan adalah menggunakan aplikasi. Resoran Pecel Lele Lela nantinya menggunakan Aplikasi pemesanan ini untuk mempercepat proses pesanan. Aplikasi ini dirancang semudah mungkin agar pelanggan tertarik dan mudah menggunakannnya. Nantinya aplikasi ini dibuat dalam bentuk tipe file APK agar mudah untuk distribusi dan di instal di hp yang berbasis android. Aplikasi ini menampilkan berbagai menu yang ada di restoran pecel lela. Sedangkan sistem operasi yang dapat menjalankan aplikasi pemesanan ini adalah android dengan versi minimal 2.2 serta API versi 8 [5].

Setiap tahunnya persaingan bisnis bidang kuliner semakin meningkat, hal ini menjadikan pemilik bisnis harus memiliki strategi baru untuk menghadirkan jumlah pengunjung pada bisnisnya. Teknologi memudahkan pengguna dalam menjalankan aktifitas dan rutinitasnya. Telnologi ini juga dapat diimplementasikan dalam sebuah bisnis kususnya yang bergerak dala bidang makanan. Sistem operasi yang terdapat pada handphone dan cukup populer di masyarakat adalah android. Android dapat digunakan sebagai client dimana pelanggan memesan menu melalui handphoneberbasis Android, tentunya aplikasi ini sudah dibuat sedemikian rupa sehingga dapat menghubungkan bagian koki dan bagia kasir dalam melakukan proses pesanan makanan atau minuman tersebut. Sistem dirancang pada bagian kasir dan koki menggunakan bahasa pemerograman PHP sehingga juda dapat di akses melalui komputer. Metode clint-server ini menggunakan berbasis Centralized DBMS Architecture sehingga data tersimpan hanya dalam satu database yang mencakup 4 entitas yaitu pelanggan, koki, kasir dan admin. pengolahan data pada sistem ini diharapkan menjadi fleksibel, terutama saat ada update 
data baik data makanann maupun data minuman [6].

\section{Metode}

Penelitian ini bertujuan untuk membuat sebuah aplikasi pemesanan makanan bagi UMKM berbasis Android. Sedangkan jenis penelitian masuk dalam kategori penelitian research and Developmen.

Pengembangan sistem ini menggunakan model waterfall. Model waterfall merupakan model yang sering digunakan dalam pengembangan perangkat lunak. Model pengembangan dengan metode ini bersifat linear artinya setiap tahap harus dilalui dan selesai kemudian baru dilanjutkan pada tahap berikutnya. Misalnya pada tahap analisis pada tahap ini yang akan dilakukan adalah melakukan analisis kebutuhan fungsional dan analisis kebutuhan non fungsional. Setelah menghasilkan dokumen analisis baru dilanjutkan ke tahap desain dab begitu seterusnya. Tahapan selanjutnya tidak akan dilaksanakan sebelum tahapan sebelumnya selesai dikerjakan dan tidak bisa mengulang ke tahap sebelumnya [7][8]. Untuk lebih jelasnya alur pengembangan sistem dengan model waterfall terlihat seperti Gambar 1.

\section{SDLC- WATERFALL MODEL}

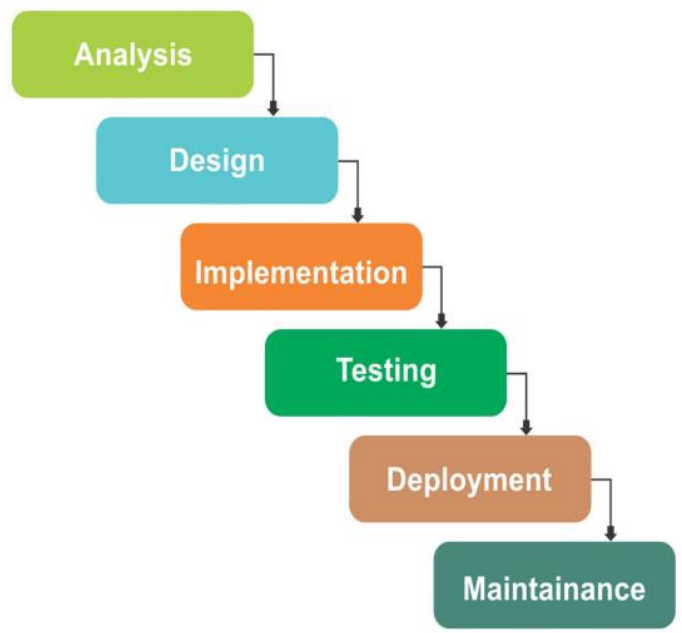

Gambar 1. Waterfall Model
Sedangkan pengumpulan data pada penelitian ini dilakukan untuk mendapatkan suatu informasi yang dibutuhkan dalam mencapai tujuan penelitian. Penelitian ini menggunakan metode observasi dan dokumentasi dalam mengumpulkan datanya. Metode observasi merupakan suatu cara mengumpulkan data dengan mengamati langsung objek yang diteliti. Sedangkan pengumpulan data dengan cara dokumentasi adalah mengumpulkan data dengan cara mengumpulkan data-data dari para pelaku UMKM yang ada di Kabupaten Ogan Komering Ulu.

\section{Hasil dan Pembahasan}

Hasil dari penelitian ini adalah sebuah aplikasi pemesanan makanan berbasis android. Aplikasi dapat digunakan oleh masyarakat dalam melakukan pemesanan makanan sesuai dengan daftar yang ada di menu. Sebelum mengakses ke menu utama aplikasi akan menampilkan splash screen. Splash screen dari aplikasi ini terlihat pada Gambar 2.

\section{0:47}

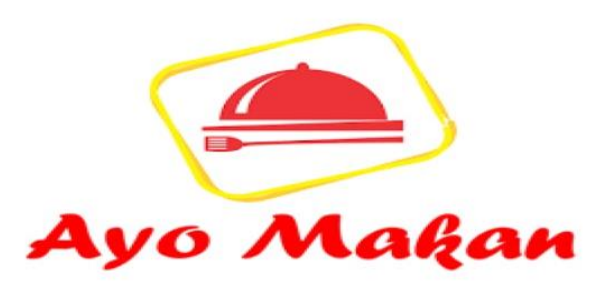

Gambar 2. Splash Screen

Aplikasi akan menampilkan menu utama setelah 4 detik menampilkan splash screen. Pada menu utama ini diambil dari 8 pelaku umkm yang bergerak dibidang makanan yaitu Nasi padang, Nasi Goreng, Pecel Lele, Bakso, Sate Kambing, Ayam Bakar, Mie Ayam dan 
pindang tulang. Adapun tampilan menu pada aplikasi ini terlihat seperti Gambar 3.

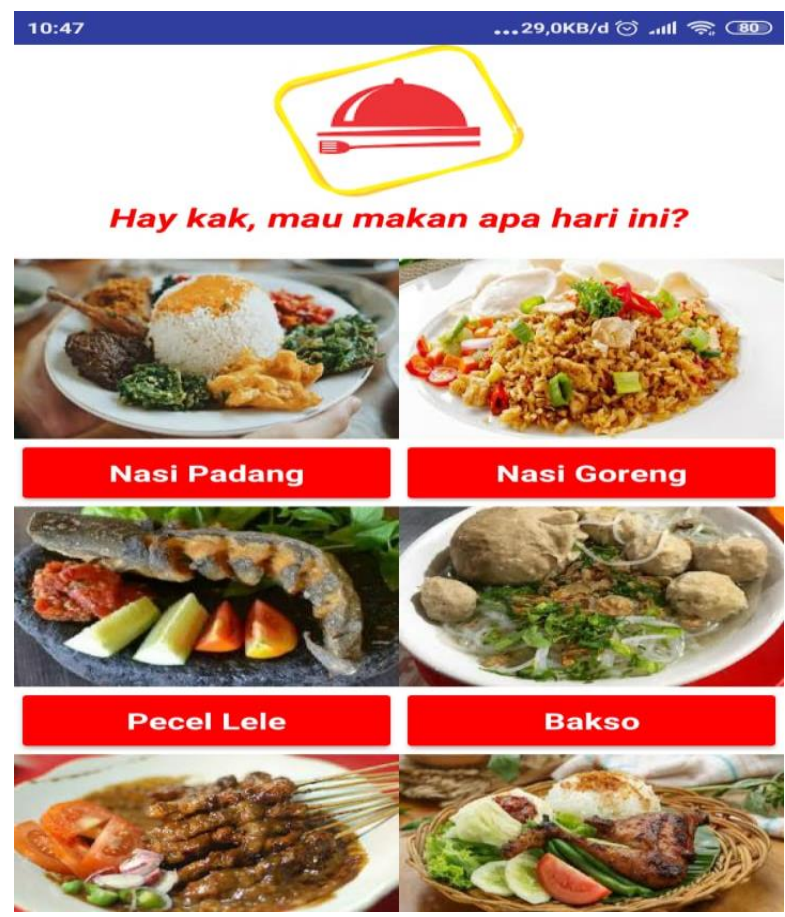

Gambar 3. Menu Makanan

Pengguna tinggal memilih makanan apa yang akan dipesan dengan cara tap tombol dibawah gambar makanan. Setelah pengguna memilih makanan yang diinginkan kemudian akan tampil nama UMKM yang penyedia makanan, nama atau variasi mananan yang dapat dipilih, jumlah makanan, pesan kepada penjual (optional). Selain itu pembeli memasukan nama, no HP dan alamat makanan yang akan diantar. Untuk lebih jelasnya terlihat seperti Gambar 4.

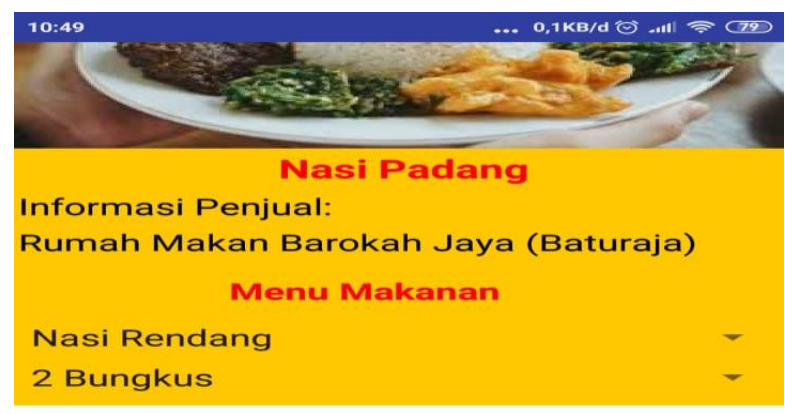

Catatan untuk penjual/admin (opsional)

\begin{tabular}{l|l} 
& \multicolumn{1}{c}{ Harga Makanan } \\
$\begin{array}{l}\text { Nama } \\
\text { Pemesan } \\
\text { No. HP } \\
\text { Alamat }\end{array}$ & Pujianto \\
\hline \multicolumn{3}{c}{ O82182889999 } \\
\hline & Jl. H.M Saleh Hasan 204 \\
\hline
\end{tabular}

Gambar 4. Proses Pemesanan
Setelah pengguna menekan tombol pesan sekarang selanjutnya sistem akan menampilkan informasi bahwa admin akan memvaliasi pesanan dengan cara menghubungi pemesan. Adapun tapmilan informasi tersebut terlihat seperti Gambar 5.
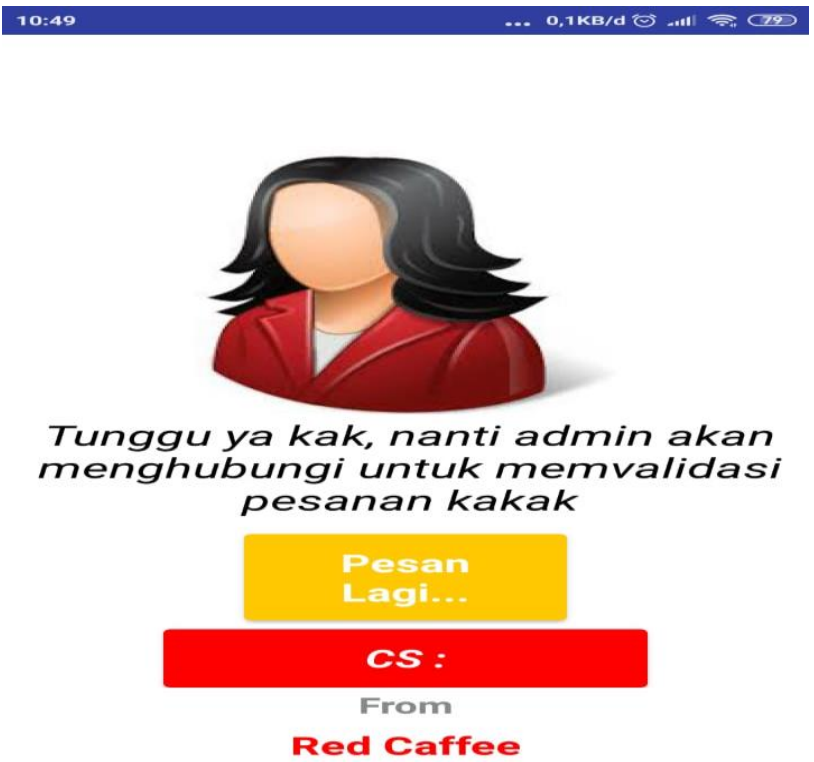

Gambar 5. Validasi admin

Setelah proses pembuatan aplikasi selesai maka dilanjutkan proses pengujian. Hasil pengujian aplikasi terlihat seperti tabel 1 .

Tabel 1. Validasi Fitur Aplikasi

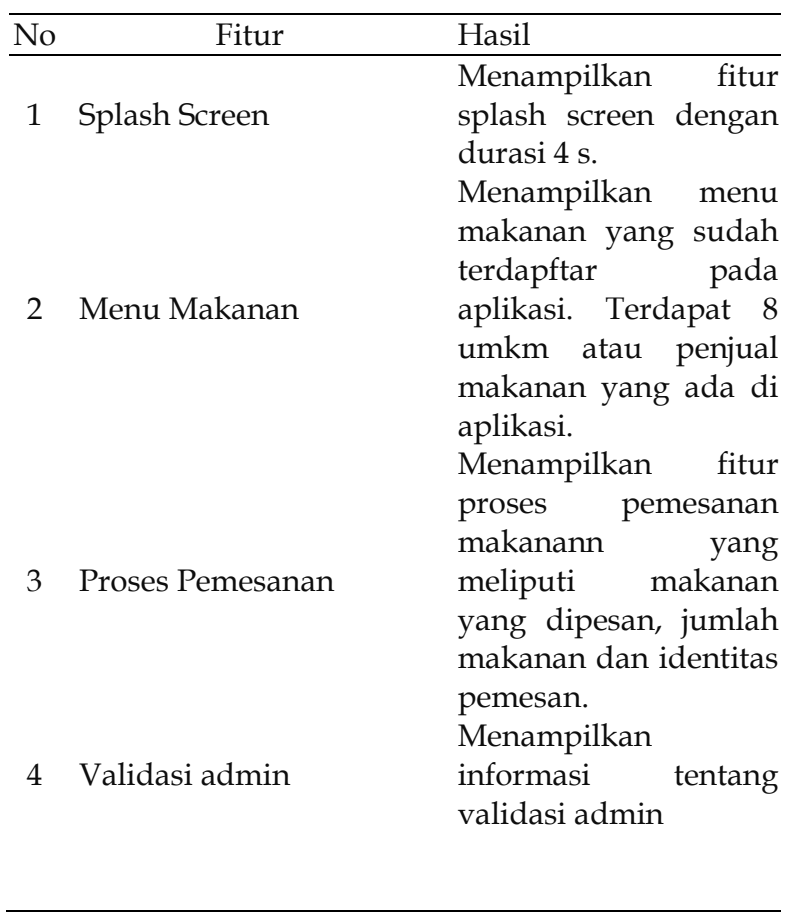




\section{Kesimpulan dan Saran}

Penelitian ini menghasilkan sebuah aplikasi pemesanan makanan yang dapat digunakan oleh pengguna dalam memesan makanan yang diinginkan sesuai dengan menu yang ditampilkan. Proses pemesanan makanan sangat simpel dan sistem akan melakukan validasi sebelum makanan dipesan ke pelaku UMKM. Sebelum sistem digunakan dilakukan pengujian terhadap aplikasi terkait fitur-fitur yang ada pada aplikasi.

Saran untuk penelitian berikutnya bahwa aplikasi dapat dikembangkan dengan menambah berbagai menu yang ada pada aplikasi. Selain menu makanan pada aplikasi dapat dikembangkan dengan menambahkan fitur menu minuman.

\section{Referensi}

[1] George Richard Payara, Radius Tanone, Penerapan Firebase Realtime Database Pada Prototype Aplikasi Pemesanan Makanan Berbasis Android, 2018, Jurnal Teknik Informatika dan Sistem Informasi Vol. 4 No.3 pp 397-406

[2] Cynthia Hayat, Enggalwiguno Rahardja dan Frans Pasamboan, Implementasi Model View Controller pada Aplikasi Pemesanan Makanan Platform Sistem Operasi Android, 2019, SATIN-Sains dan Teknologi Informasi, Vol. 5, No. 1, pp 1926
[3] Farida Nurlaila, Aplikasi Pemesanan Makanan pada Restoran 1953 Indonesia Berbasis Web, 2019, Jurnal Informatika Universitas Pamulang Vol. 4, No. 1. pp 16-22

[4] Steven Yurie Frediyatma, Aplikasi Pemesanan Makanan Berbasis Cloud dengan Platform Android, 2014, MERPATI VOL. 2, NO. 1, pp 118- 126

[5] Busran, Wina Anggraini, Perancangan Aplikasi Pemesanan Makanan Dan Minuman Berbasis Sistem Operasi Android (Studi Kasus : Pecel Lele Lela), 2016, Jurnal TEKNOIF Vol. 4 No. 1 pp 5766

[6] Deni Utama, Asahar Johar, Funny Farady Coastera, Aplikasi Pemesanan Makanan dan MinumanRestaurant Berbasis Client Serverdengan PlatformAndroid dan PHP Menggunakan Metode Centralized DBMS Architecture (Studi Kasus: Cafe Cempakoe Kota Bengkulu), 2016, Jurnal Rekursif, Vol. 4 No. 3, pp 288-300

[7] R. Susanto and A. D. Andriana,-Perbandingan Model Waterfall Dan Prototyping Untuk Pengembangan Sistem Informasi, $\|$ Maj. Ilm. UNIKOM, vol. 14,no. 1, pp. 41-46, 2016

[8] Z. R. saputra Elsi, -Perancangan Aplikasi Pengolahan Data Obat Berbasis Mysql Dengan Client Server,I J. Digit. Teknol. Inf., vol. 2, no. 1, p. 43, Mar. 2019, doi:10.32502/digital.v2i1.2486 